\title{
Population genetic structure of the parasitic nematode Spirocerca lupi in South Africa
}

Jaco M. Greeff ${ }^{\mathrm{a}, 1^{*}}$, Kerry Reid ${ }^{\mathrm{a}, 1,2}$, Janishtha R. Gagjee ${ }^{\mathrm{a}}$, Sarah J. Clift ${ }^{\mathrm{b}}$, Pamela J. de Waal ${ }^{\mathrm{a}, 1}$

${ }^{a}$ Department of Biochemistry, Genetics and Microbiology, University of Pretoria, Pretoria 0002, South Africa

bection Pathology, Department of Paraclinical Sciences, Faculty of Veterinary Science, University of Pretoria, Pretoria 0002, South Africa

${ }^{1}$ These authors contributed equally to the research

${ }^{2}$ Present Address: Ecology and Evolutionary Biology Department, University of California, Santa Cruz, 95060, USA

*Corresponding author: J M Greeff, Tel.: +27124203260; fax: +27123625327

Postal address: Department of Biochemistry, Genetics and Microbiolgy, University of Pretoria, Pretoria, 0002, South Africa

E-mail address: jaco.greeff@up.ac.za

\section{Highlights}

- Genotyped 9 microsatellites in 130 Spirocerca lupi nematodes from three regions.

- Spirocerca lupi worms disperse effectively over long distances $(>100 \mathrm{~km})$.

-Worms from different hosts amalgamate frequently.

- Inbreeding stems from matings between a few worms in each host.

-Worms from a host are more closely related than worms between hosts. 


\section{Graphical Abstract}
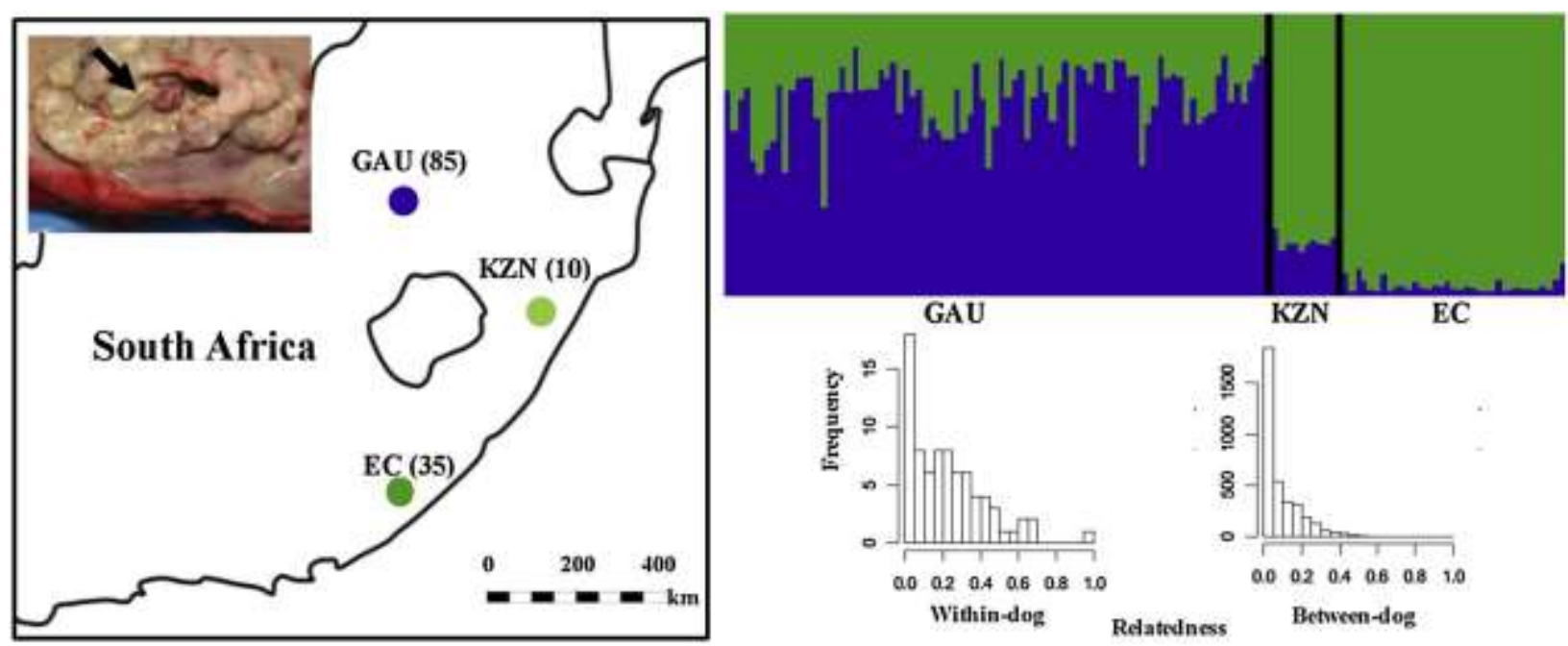

\section{ABSTRACT}

Spirocerca lupi is a parasitic nematode of canids and occurs in most tropical and subtropical regions around the world. While its life cycle is well known, insight is lacking about its mating structure within-hosts, genetic variability and long-distance dispersal ability. These characteristics contribute significantly to the dynamics and spread of potential resistance genes, which impacts on the control of S. lupi. To evaluate the population structure and infer potential mating behaviour of $S$. lupi, we genotyped 130 samples at nine microsatellite loci from three geographical locations in South Africa, between 600 and $1000 \mathrm{~km}$ apart. These loci identified unique individuals with high levels of polymorphism suggesting that these are not newly established S. lupi populations in South Africa and that effective population sizes must be large. Population genetic analyses showed that populations are not very distinct, that worms within dogs are more similar to each other than random worms from each population, and that mating is at random within dogs. We can thus infer that the parasite is frequently transported over great distances. Even so, two genetically distinct populations could be identified. Relatedness of 
worms within dogs were significantly higher than between dogs and together with $F$-statistics suggests some non-random transmission of parasites between hosts. While mating is random within a host, parasites from a host are more likely to be related and hence an increase in homozygosity is seen. The implications of this genetic structure on parasite control are considered.

Keywords: canids, gene flow, microsatellites, $F$-statistics, population structure, relatedness

\section{Introduction}

The canine oesophageal worm, Spirocerca lupi, is a parasitic nematode that infects carnivores, predominately the domestic dog (Bailey, 1972; Soulsby, 1982). It is important because of the poor prognosis in the untreated final host (Oryan et al., 2008; van der Merwe et al., 2008) and because it occurs on all continents except Antarctica (Fitzsimmons, 1960; van der Merwe et al., 2008). Potential increases in prevalence (Mazaki-Tovi et al., 2002; Kok et al., 2011; Aroch et al., 2015) and distribution (Al-Sabi et al., 2014; Giannelli et al., 2014; Wright et al., 2016) add to the potential threat posed by S. lupi. Knowledge of S. lupi's life cycle has been exploited to control the parasite (Bailey, 1972; van der Merwe et al., 2008). By augmenting this knowledge with a molecular population genetic approach, we can quantify transmission dynamics of the parasite further and predict how resistance may develop and spread (Criscione et al., 2010; Beesley et al., 2017).

Transmission of the parasite can be prevented at two points in its life cycle. The life cycle has been summarized by many (Bailey, 1972; Soulsby, 1982; van der Merwe et al., 2008) as follows - eggs of $S$. lupi are released in the faeces of the final host (canine). If these eggs are 
ingested by dung beetles that are the intermediate host, the eggs develop to the third larval stage. To continue the life cycle, infected beetles must be eaten by either the final host or a paratenic host (including lizards, poultry, various wild birds and small mammals). If a paratenic host eats the larvae, they will briefly excyst but then re-encyst. If the final host consumes an infected paratenic or intermediate host, larval development continues and is completed. The adult worms live within nodules in the oesophageal wall of the definitive host. Here they mate and females lay eggs in the oesophageal lumen that pass out in the host faeces. The lifecycle can thus be broken by picking up dog faeces, which severs the link provided by dung beetles (van der Merwe et al., 2008) and by not feeding raw remains of potential paratenic hosts to dogs, which eliminates the link that paratenic hosts play (Bailey, 1972).

Any single or combination of the hosts - intermediate, paratenic and final, can disperse the parasite; but how effective this dispersal is, and over what distances they travel are unclear. In a study on $S$. lupi that included samples from a $25 \mathrm{~km}$ x $15 \mathrm{~km}$ area, the mitochondrial cox 1 gene showed no geographical structure suggesting that dispersal is in excess of 10's of kms (de Waal et al., 2012). To quantify dispersal over longer ranges, samples need to be compared from more distant localities (Ebbs et al., 2016).

Any S. lupi population is divided into smaller populations confined to hosts, so-called infrapopulations (Margolis et al., 1982). While worms are not able to disperse by themselves, their hosts' dispersal and feeding behavior will determine the worms' population structure. Infrapopulations can be admixed when a host feeds on more than one infected intermediate or paratenic host or when a beetle consumes infected faeces from more than one infected dog. If in this way, eggs and/or larvae are sufficiently mixed during infection all infrapopulations would form one genetic population. On the other extreme, if eggs and/or larvae from different sources 
never mix, then each infrapopulation is a genetic unit called a deme. These are two extremes between which reality lies. As a result, the fraction of genetic variation between and within infrapopulations depends on the amount of mixing (Nadler, 1995; Hedrick, 2000; Paterson et al., 2000; Prugnolle et al., 2002; Théron et al., 2004; Criscione et al., 2005, 2010; Prugnolle et al., 2005a, 2005b; Criscione and Blouin, 2006; Steinauer et al., 2010; de Waal et al. 2012). When there is limited mixing of infrapopulations, genetic drift will cause infrapopulations to become different from one another over time (Wright, 1931). Such genetic drift will increase differences between infrapopulations and will reduce the genetic variation within infrapopulations (Wright, 1931). The impact of genetic drift is more severe when populations are small (Wright, 1931) and S. lupi has small infrapopulations. The harmonic mean population size in the intermediate host is only 6 individuals at the most (du Toit et al., 2008; de Waal et al., 2012) and the mode is between 6 and 12 for the final host (Fitzsimmons, 1960). Random mating within the infrapopulation will result in a Hardy-Weinberg equilibrium within the infrapopulation. However, since members of the infrapopulation are related, such random mating will inevitably result in an excess of homozygosity at the population level.

de Waal et al. (2012) inferred frequent admixture would be required to explain the high mitochondrial diversity observed in infrapopulations. Since mitochondria are maternally inherited de Waal et al. (2012) only measured the female population's dynamics and could not reveal the degree of inbreeding in worms. Nuclear microsatellites can overcome these shortcomings of mitochondrial DNA.

Intermediate levels of admixture among small infrapopulations results in a mixture of matings between unrelated individuals on the one side and between relatives on the other (mixed mating system). The consequence of such inbreeding is that even rare recessive alleles can be 
homozygous and selection can favour such alleles (Wright, 1921). In the context of parasites, this means that even if resistance alleles are recessive, they can be selected for and increase rapidly (Criscione et al., 2010; Beesley et al., 2017). Co-dominant nuclear markers such as microsatellites can be used to quantify inbreeding as well as relatedness between worms.

To evaluate the population structure over a large spatial scale in South Africa and to provide insight about relatedness between worms between and within hosts, we did a population genetics study of 130 worms from 47 dogs from three populations that are between 600 and 1000 km apart using nine previously developed microsatellites (Reid et al., 2015).

\section{Materials and methods}

\subsection{Sample collection, DNA extraction and microsatellite amplification}

Veterinarians collected S. lupi samples from necropsies of naturally infected Canis familiaris which had passed away from complications of $S$. lupi infections in three populations in South Africa from 2005 to 2009. The populations are in three different provinces namely, Gauteng (Tshwane Metropole - 85 specimens), Kwa-Zulu Natal (Durban - 10 specimens) and the Eastern Cape (Grahamstown - 35 specimens) (Fig. 1A). In order to quantify within-dog variation, three worms from each dog were genotyped, where possible. We will refer to the three different regions as populations and to worms from different host dogs as infrapopulations.

We extracted DNA from tissue samples not exceeding $25 \mathrm{mg}$ from each worm with the Qiagen DNeasy blood and tissue kit (Qiagen, California) following the manufacturers specifications. Nine microsatellite loci were amplified and genotyped in all specimens in a single diagnostic multiplex as described in Reid et al. (2015). 
A

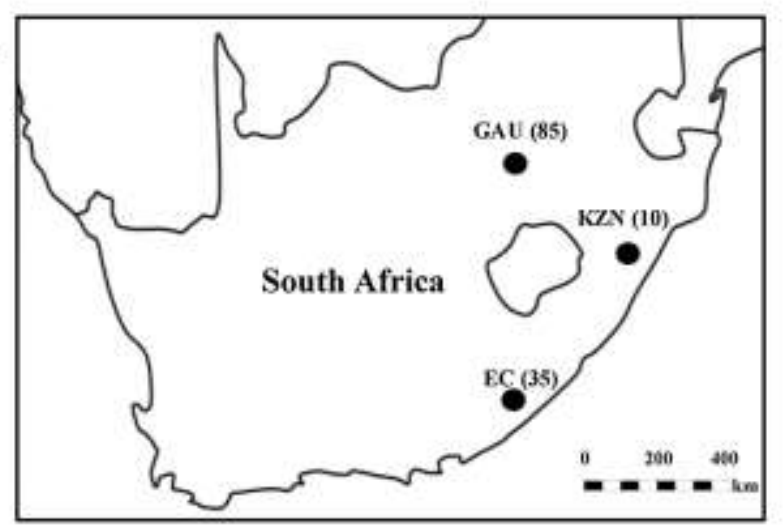

B

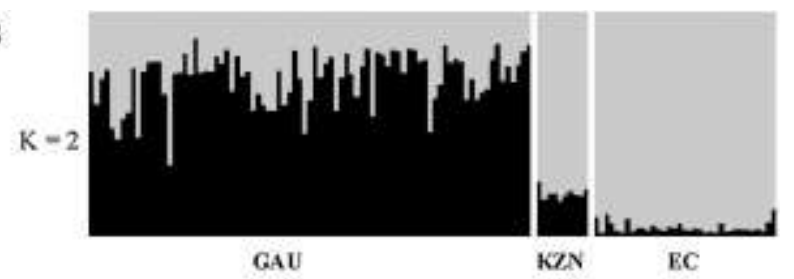

C

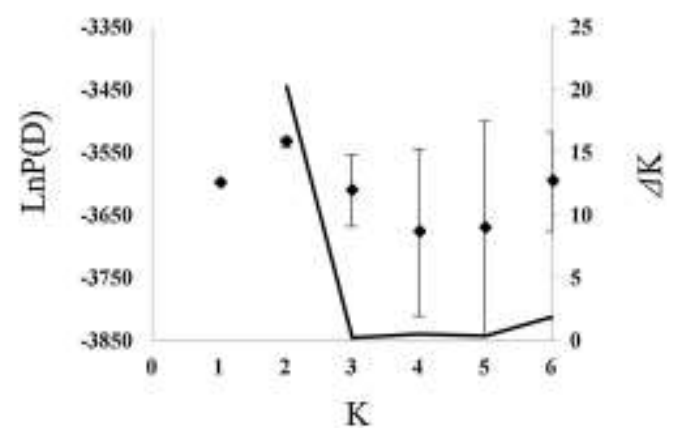

Fig. 1. Sampling locations and geographic structuring of Spirocerca lupi from South Africa. A) Map of South Africa indicating the sampling locations and number of worms per population GAU - Tshwane metropole in Gauteng, KZN - Durban in Kwa-Zulu Natal and EC - Grahamstown in the Eastern Cape. B) STRUCTURE plot of K = 2 C) Likelihood (LnP(D), filled circles and error bars) and Delta $\mathrm{K}(\Delta \mathrm{K}$, solid line) plots.

Microsatellite loci were genotyped on an ABI3500 at the sequencing facility of the University of Pretoria (South Africa). Twenty-two individuals were re-genotyped to estimate scoring error and to confirm the consistency of migration of individual alleles. We scored microsatellite loci using GENEMARKER version 2.4.0 (SoftGenetics, State College, Pennsylvania, USA).

\subsection{Data analysis}

We calculated several summary statistics in GENETIX version 4.05.2. (Belkhir et al., 1996-2004) and included the number of alleles, expected heterozygosity $\left(H_{\mathrm{E}}\right)$, observed heterozygosity $\left(H_{\mathrm{O}}\right)$ and Weir and Cockerham's (1984) inbreeding coefficient $\left(F_{\mathrm{IS}}\right)$ for each population and over all populations. Allelic richness $\left(A_{\mathrm{R}}\right)$ was calculated in FSTAT version 1.2 
(Goudet, 1995) to compare levels of genetic diversity taking into account the difference in sample sizes.

The geographic structuring of $S$. lupi between populations was assessed by calculating genetic differentiation ( $F_{\mathrm{ST}}$; Weir and Cockerham, 1984) in GENETIX with 200 permutations, as well as Jost's $D$ between the sampling locations using SMOGD version 1.2.5 (Crawford, 2010).

We used analysis of molecular variance (AMOVA), as implemented in ARLEQUIN version 3.5.1 (Excoffier and Lischer, 2010), to calculate $F$-statistics with the default locus-bylocus method (see supplementary text for interpretation of $F$-statistics). Four infrapopulations each containing a single worm with one or more loci that failed were excluded. We calculated these statistics at all three levels of hierarchical structure of alleles - individuals, dogs (or infrapopulations) and populations (three localities). The data was recoded in $\mathrm{R}$ ( $\mathrm{R}$ Core Team

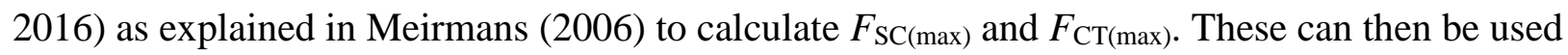
to calculate corrected measures: $F_{\mathrm{SC}}^{\prime}=F_{\mathrm{SC}} / F_{\mathrm{SC}(\max )}$ and $F_{\mathrm{CT}}^{\prime}=F_{\mathrm{CT}} / F_{\mathrm{CT}(\max )}$.

The correlation between $G_{\mathrm{ST}}$ (an $F_{\mathrm{ST}}$ analogue) and $H_{\mathrm{S}}$ over loci was calculated using CoDiDi (Wang, 2015) and a Pearson's product-moment correlation in R (R Core Team, 2016). First, we considered the role of mutations at a local level by analysing the two larger populations (Grahamstown and Tshwane Metropole) separately, and taking into account divisions into infrapopulations. Second, we estimated the role of mutations at a larger scale by combining all three populations.

In addition, we used STRUCTURE version 2.3.4 (Pritchard et al., 2000) to assess population structure by using a Bayesian approach to infer the most likely number of populations. We used an admixture model, with sampling locations as prior (Hubisz et al., 2009) and correlated allele frequencies. Runs for $K=1-6$ were carried out each with 2000000 Markov 
Chain Monte Carlo iterations allowing a burn-in period of 200000 iterations. We kept default values for all other parameters. The program STRUCTURE HARVESTER (Earl and von Holdt, 2012) was used to apply the Evanno method ( $\Delta K$, Evanno et al., 2005) to detect the value of $K$, the number of genetic groups that best fit the data.

We estimated inbreeding coefficients separately for each of the two larger populations with the trio maximum likelihood method in COANCESTRY (Wang, 2011) to avoid a Wahlund effect. We calculated relatedness between worm pairs from the two populations with larger sample numbers (Tshwane Metropole and Grahamstown). Since there may be a Wahlund effect between these localities, relatedness was calculated for each population separately estimating allele frequencies from the data. We used Wang's (2011) trio maximum likelihood estimate as implemented in COANCESTRY (Wang, 2011) which accounts for inbreeding. We separated relatedness estimates into two categories - between worms from the same dog host $\left(R_{\mathrm{w}}\right)$ and between worms from different dog hosts $\left(R_{\mathrm{b}}\right)$. To determine if the $R_{\mathrm{w}}$ estimates are significantly higher than $R_{\mathrm{b}}$, we permuted relatedness values 10000 times randomly to the same number of within and between dog comparisons to obtain a null distribution of the difference in $\mathrm{R}$ (R Core Team, 2016). We compared the actual difference to this null distribution.

\section{Results}

The diversity estimates are summarized in Table 1 and indicated similar levels of heterozygosity between locations. The average observed heterozygosity was slightly lower than the expected heterozygosity in the largest population, while the small difference in these parameters were in the opposite direction for the two smaller populations. While the number of 
Table 1. Summary of standard population genetics analyses for each population of Spirocerca lupi.

\begin{tabular}{|c|c|c|c|c|c|c|c|c|c|c|c|c|c|c|c|c|c|c|c|c|}
\hline \multirow[b]{2}{*}{ Locus } & \multicolumn{5}{|c|}{ Total $^{\mathrm{a}}$} & \multicolumn{5}{|c|}{ Tshwane $(\mathrm{n}=85)$} & \multicolumn{5}{|c|}{ Durban $(n=10)$} & \multicolumn{5}{|c|}{ Grahamstown $(\mathrm{n}=35)$} \\
\hline & $\mathrm{N}_{\mathrm{A}}$ & $\mathrm{A}_{\mathrm{R}}$ & $\mathrm{H}_{\mathrm{E}}$ & $\mathrm{H}_{\mathrm{O}}$ & $\mathrm{F}_{\mathrm{IS}}$ & $\mathrm{N}_{\mathrm{A}}$ & $\mathrm{A}_{\mathrm{R}}$ & $\mathrm{H}_{\mathrm{E}}$ & $\mathrm{H}_{\mathrm{O}}$ & $\mathrm{F}_{\mathrm{IS}}$ & $\mathrm{N}_{\mathrm{A}}$ & $\mathrm{A}_{\mathrm{R}}$ & $\mathrm{H}_{\mathrm{E}}$ & $\mathrm{H}_{\mathrm{O}}$ & $\mathrm{F}_{\text {IS }}$ & $\mathrm{N}_{\mathrm{A}}$ & $\mathrm{A}_{\mathrm{R}}$ & $\mathrm{H}_{\mathrm{E}}$ & $\mathrm{H}_{\mathrm{O}}$ & $\mathrm{F}_{\mathrm{IS}}$ \\
\hline SL02 & 9 & 4.7 & 0.68 & 0.65 & 0.05 & 9 & 4.9 & 0.72 & 0.68 & 0.05 & 3 & 3 & 0.56 & 0.75 & -0.29 & 5 & 3.9 & 0.57 & 0.56 & 0.03 \\
\hline SL04 & 6 & 3.6 & 0.47 & 0.47 & 0.02 & 6 & 3.8 & 0.45 & 0.43 & 0.04 & 4 & 3.8 & 0.51 & 0.44 & 0.19 & 4 & 3.4 & 0.51 & 0.54 & -0.06 \\
\hline SL06 & 8 & 5.4 & 0.79 & 0.65 & 0.19 & 8 & 3.6 & 0.79 & 0.66 & 0.18 & 4 & 3.6 & 0.51 & 0.7 & -0.33 & 7 & 4.9 & 0.74 & 0.62 & 0.18 \\
\hline SL10 & 10 & 4.9 & 0.73 & 0.6 & 0.18 & 9 & 3.7 & 0.76 & 0.58 & 0.24 & 4 & 3.7 & 0.42 & 0.4 & 0.09 & 6 & 4.7 & 0.66 & 0.71 & -0.05 \\
\hline SL13 & 9 & 4.8 & 0.68 & 0.73 & -0.07 & 9 & 5 & 0.67 & 0.74 & -0.09 & 5 & 5 & 0.66 & 0.75 & -0.06 & 5 & 4.5 & 0.67 & 0.7 & -0.02 \\
\hline SL14 & 18 & 7.1 & 0.83 & 0.86 & -0.03 & 17 & 7.8 & 0.83 & 0.83 & 0.01 & 8 & 7.8 & 0.85 & 1 & -0.15 & 7 & 4.8 & 0.72 & 0.88 & -0.21 \\
\hline SL15 & 13 & 5.1 & 0.56 & 0.47 & 0.16 & 12 & 5.9 & 0.67 & 0.57 & 0.16 & 4 & 3.7 & 0.37 & 0.44 & -0.12 & 5 & 2.5 & 0.21 & 0.23 & -0.06 \\
\hline SL17 & 9 & 5.2 & 0.77 & 0.63 & 0.19 & 9 & 5.5 & 0.77 & 0.69 & 0.11 & 5 & 4.7 & 0.68 & 0.5 & 0.31 & 4 & 3.8 & 0.72 & 0.52 & 0.3 \\
\hline SL18 & 7 & 5 & 0.78 & 0.88 & -0.13 & 7 & 5.2 & 0.78 & 0.87 & -0.1 & 4 & 3.9 & 0.66 & 0.9 & -0.33 & 6 & 4.6 & 0.75 & 0.91 & -0.21 \\
\hline $\mathrm{All}^{\mathrm{b}}$ & 9.8 & - & 0.7 & 0.66 & - & 9.5 & - & 0.72 & 0.67 & - & 4.5 & - & 0.58 & 0.65 & - & 5.4 & - & 0.62 & 0.63 & - \\
\hline
\end{tabular}

$\mathrm{N}_{\mathrm{A}}$ : number of alleles; $\mathrm{A}_{\mathrm{R}}$ : Allelic Richness, based on 8 samples; $\mathrm{H}_{\mathrm{E}}$ : expected heterozygosity; $\mathrm{H}_{\mathrm{O}}$ : observed heterozygosity; $\mathrm{F}_{\mathrm{IS}}$ : inbreeding coefficient.

${ }^{\text {a }}$ Total values are calculated per locus over all samples.

${ }^{b}$ The last row indicates the mean values calculated over all the loci. $A_{R}$ is based on 8 samples. 
alleles was the highest for the largest sample, allelic richness indicated similar levels of diversity between populations (Table 1).

Weir and Cockerham's (1984) $F_{\text {ST }}$ estimates suggest that while the three populations are genetically distinct, the differences are small. Specifically, between Gauteng and Kwa-Zulu Natal, $F_{\mathrm{ST}}=0.037(\mathrm{p}<0.001)$, between Gauteng and Eastern Cape, $F_{\mathrm{ST}}=0.035(\mathrm{p}<0.001)$ and between Kwa-Zulu Natal and Eastern Cape, $F_{\mathrm{ST}}=0.045(\mathrm{p}<0.001)$. Jost's $D$ estimates suggested similar differences except that the Kwa-Zulu Natal-Eastern Cape comparison was smaller than the other two (Gauteng and Kwa-Zulu Natal 0.043, Gauteng and Eastern Cape 0.044 and between Kwa-Zulu Natal and Eastern Cape 0.029).

While $F_{\text {IS }}$ was slightly negative it was not significantly different from zero (Table 2 ). On the other hand, $F_{\text {IT }}$ was significantly larger than zero suggesting that either infrapopulations and/or populations are sufficiently different from one another to cause a Wahlund effect (Table 2). The AMOVA suggests that this is predominantly caused by differences between infrapopulations because $F_{\mathrm{SC}}$ and $F_{\mathrm{SC}}^{\prime}$ are respectively substantially larger than $F_{\mathrm{CT}}$ and $F_{\mathrm{CT}}^{\prime}$ (both $F_{\mathrm{SC}}$ and $F_{\mathrm{CT}}$ are significantly larger than zero, Table 2$)$. The correlation between diversity $\left(H_{\mathrm{S}}\right)$ and differentiation $\left(G_{\mathrm{ST}}\right)$ as calculated by CoDiDi (Wang, 2015) showed no significant negative correlations either from worms within dogs in Tshwane metropole $(\rho=-0.231, p=0.55)$ or in Grahamstown $(\rho=0.019, p=0.96)$ or comparing populations $(\rho=0.118, p=0.76)$. The lack of significance suggests that demographic processes outweigh mutation. The corrected estimate of $F_{\mathrm{CT}}, F_{\mathrm{CT}}^{\prime}=0.095$ is three times higher (Table 2). Together, these data suggest that allele frequencies between populations are so similar that long-distance dispersal occurs frequently; that while there is admixture of infrapopulations, it is infrequent enough to render infrapopulation allele frequencies different from one another. As a result, even though worms 
mate randomly within hosts, they do not appear to mate randomly within the population and at this level some inbreeding occurs.

Table 2. $F$-statistic estimates from AMOVA, without and with a correction for the maximum estimates based on recoded data different from 0 .

\begin{tabular}{ccc}
\hline$F$-statistic & Estimate & $\begin{array}{c}\text { Corrected } \\
\text { estimates }\end{array}$ \\
\hline$F_{\mathrm{IS}}$ & -0.064 & \\
$F_{\mathrm{SC}}$ & $\mathbf{0 . 1 0 0}^{\mathrm{a}}$ & $F_{\mathrm{SC}}^{\prime}=0.265$ \\
$F_{\mathrm{CT}}$ & $\mathbf{0 . 0 3 0}$ & $F_{\mathrm{CT}}^{\prime}=0.095$ \\
$F_{\mathrm{IT}}$ & $\mathbf{0 . 0 7 1}$ & \\
\hline a bold indicate estimates significantly different from 0.
\end{tabular}

STRUCTURE identified two clusters, one consisting of the Gauteng samples and the other of the Eastern Cape and Kwa-Zulu Natal samples, with no additional sub-structuring observed (Fig. 1B and Fig. 1C).

Individual inbreeding coefficients $(F)$ for the 85 worms from Tshwane metropole and 35 from Grahamstown were similar with means of 0.126 and 0.107 and varied between 0 and 0.646 , and 0 and 0.756 , respectively (Fig. 2). Note that while some worms are indeed inbred, the majority have very low inbreeding coefficients and the distribution is multimodal (Fig. 2). These observations suggest a mixed mating system.

The mean estimates of relatedness for the $78 R_{\mathrm{w}}$ and $3492 R_{\mathrm{b}}$ values in Tshwane metropole were 0.22 and 0.08 respectively, and closely resembled estimates from Grahamstown, 0.21 and 0.12 respectively. Relatedness of worms from the same dog were significantly higher than relatedness of worms from different dogs for both localities (permutation test: $\mathrm{p}<0.0001$; Fig. 3). Relatedness values within dogs varied with modes that may correspond to unrelated individuals, half sibs and full sibs (Fig. 3a \& 3b). The relatedness of worms within dogs were 
almost twice the coefficient of kinship (or $F_{\mathrm{SC}}, 0.215 \sim 2 \mathrm{x} 0.100$ ) as expected (Pamilo and Crozier, 1982).

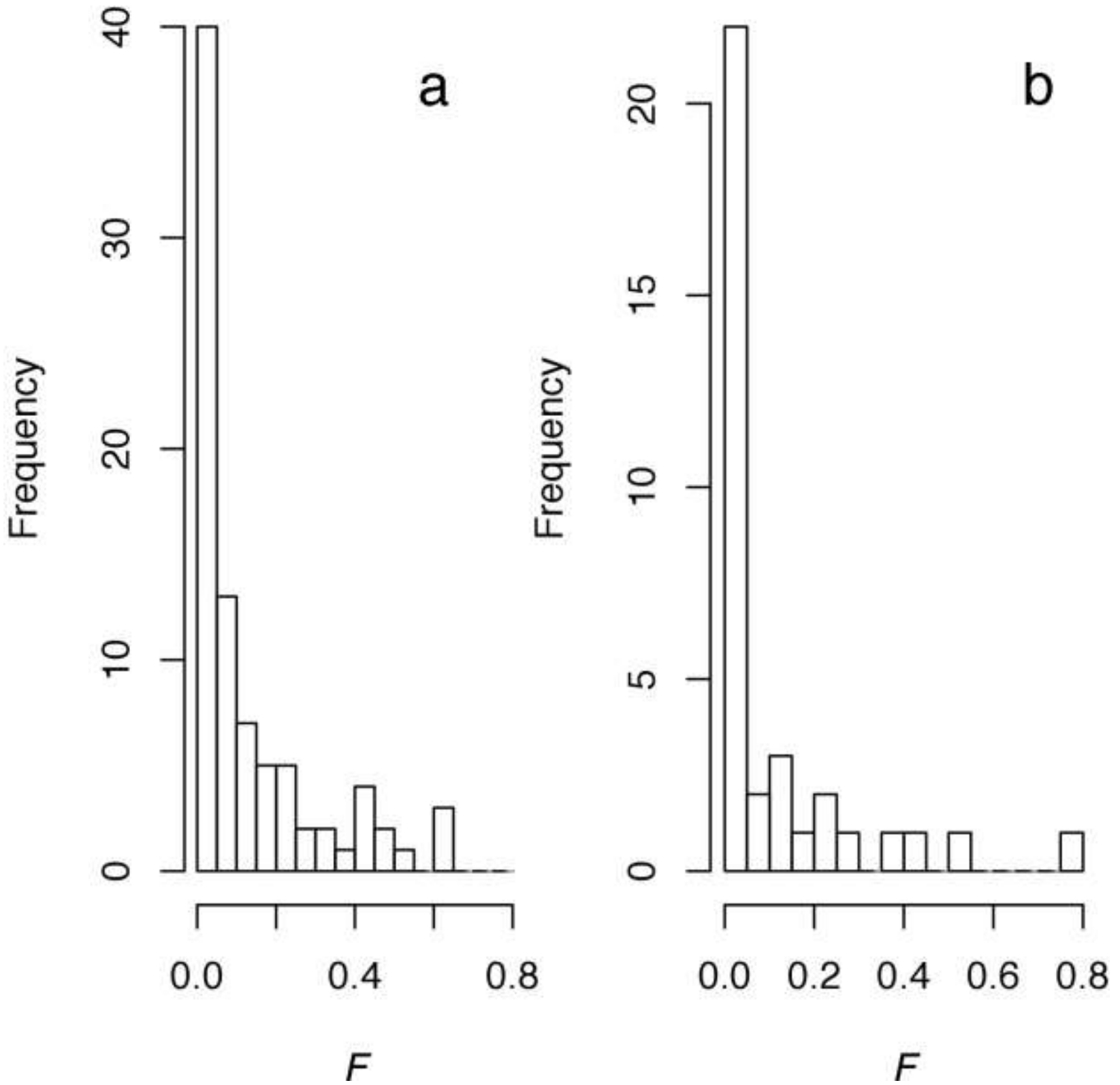

Fig. 2. Individual inbreeding coefficients of Spirocerca lupi worms using COANCESTRY for two populations: (a) Gauteng, (b) Eastern Cape. 

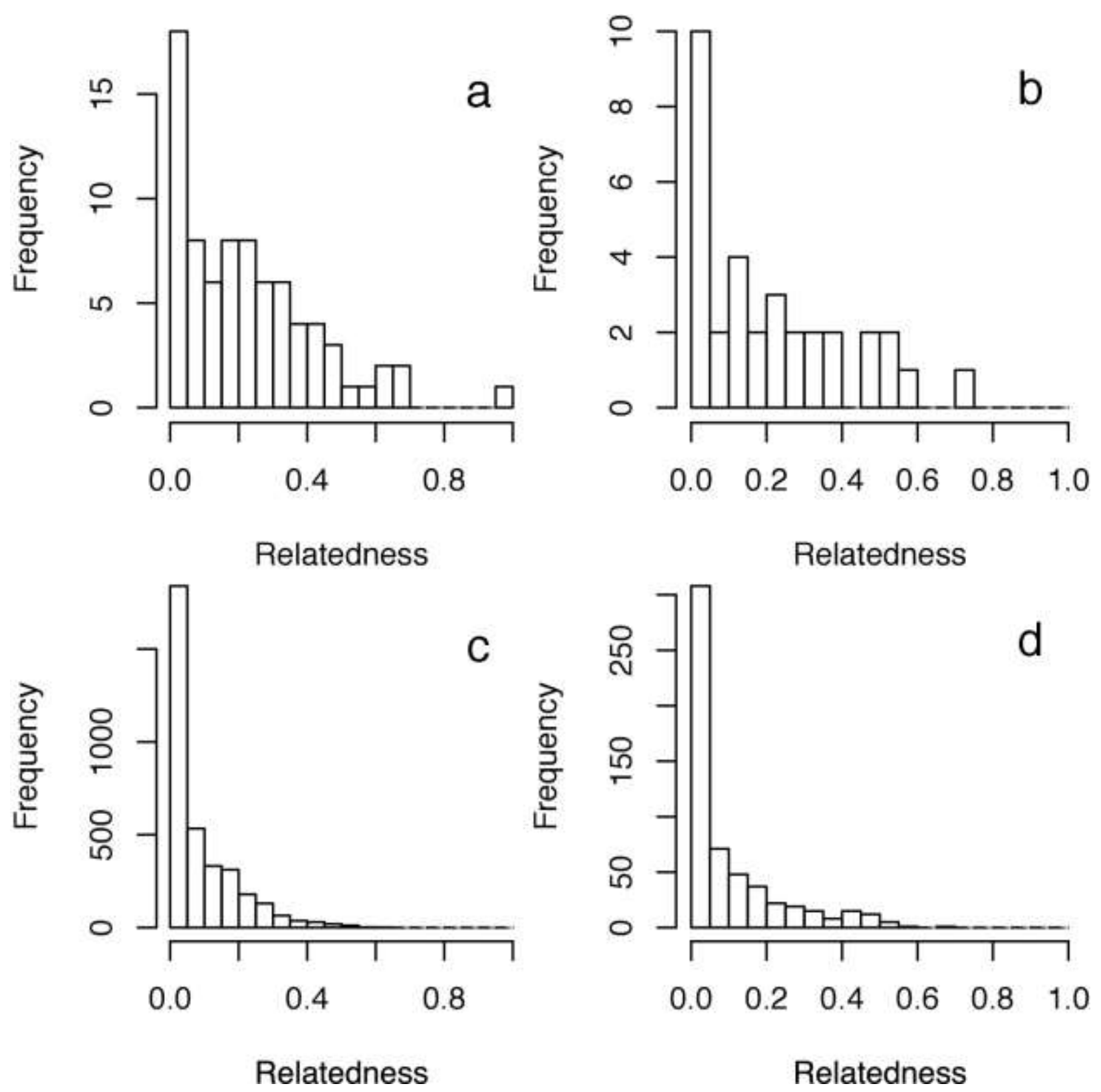

Fig. 3. Relatedness of pairs of Spirocerca lupi worms drawn from the same $\left(\mathrm{R}_{\mathrm{w}}\right.$, a \& $\left.\mathrm{b}\right)$ and drawn from different $\operatorname{dogs}\left(\mathrm{R}_{\mathrm{b}}, \mathrm{c} \& \mathrm{~d}\right)$ from Gauteng $(\mathrm{a} \& \mathrm{c})$ and Eastern Cape $(\mathrm{b} \& \mathrm{~d})$. 


\section{Discussion}

In combination, the data suggests a genetically variable population with effective dispersal over long ranges (100's of km). While worms from different dogs are significantly different from one another, admixture and dispersal must occur frequently. The facts that worms from some infrapopulations are related whereas others are not, and that some worms are inbred whereas others are not, is consistent with the idea that $S$. lupi has small infrapopulations that undergo frequent admixture.

The high variation observed here at nuclear markers in combination with mitochondrial data (de Waal et al., 2012) suggests a persistent and large population. The first archaeological evidence of domestic dogs in southern Africa dates back to some 1500 years ago (Greyling et al., 2004) and our data do not contradict the view that $S$. lupi may have been part of this association from the very beginning.

The similarity between populations may reflect the mutational process rather than high levels of migration, but the CoDiDi analyses cast doubt on this conclusion. $F_{\mathrm{CT}}^{\prime}$ is substantially higher than $F_{\mathrm{CT}}$, but suggests 7.5 migrants per worm generation $(=(1-0.095) /(4 \times 0.03)$; Meirmans and Hedrick 2011). While this estimate relies on unrealistic assumptions (Whitlock and McCauley 1999), the implication is high gene flow between populations. Given that the infrapopulation sizes are between 6 and 12 worms (Fitzsimmons, 1960; du Toit 2008), it means that at least one infected host needs to migrate between these localities per worm generation. Similar high gene flow was observed for Fasciola hepatica (Beesley et al., 2017) where hosts are routinely moved over large distances. Since parasite gene flow relies on host movement (Criscione et al., 2005; Ebbs et al., 2016), the implication is that dogs and/or beetles are mobile. 
STRUCTURE analyses and Jost's $D$ supports a view of low differentiation between populations. These findings show that if a new mutation conferring drug resistance arose it will rapidly spread over distances of 100's of kilometers.

The tussle between genetic drift, which reduces infrapopulation genetic variation, and admixture, which has the opposite effect, suggests frequent admixture but not panmixia. A lack of panmixia at a population level is reflected in the significant value of $F_{\mathrm{SC}}(=0.100)$ that measures the differentiation between infrapopulation within a population. De Waal et al.'s (2012) estimate of $\varphi$ sc (equivalent of $\left.F_{\mathrm{SC}}\right)=0.272$ for a mitochondrial gene translates to 0.068 $(=0.272 / 4)$ for nuclear genes. It also suggests significant structure at the level of infrapopulations. This lack of panmixia can stem from either hosts being sampled from isolated subpopulations or from clumped transmission of infrapopulations. A lack of local population structure (de Waal et al. 2012) and low $F_{\mathrm{CT}}$ between populations suggest that isolated subpopulations do not exist and that $F_{\mathrm{SC}}$ stems from clumped transmission of infrapopulations. The fact that within host relatedness is higher than between host relatedness further supports a view that infrapopulations are not one panmictic entity. The infrapopulations of $S$. lupi admix less than those of several other parasites (Criscione and Blouin 2006; Criscione et al., 2010; Johnson et al., 2006; Beesley et al., 2017). While populations are not panmictic, frequent admixture will ensure that new resistant mutations can effectively spread locally.

The AMOVA estimate of $F_{\text {IS }}$ that is not different from zero (Table 2) suggesting that mating is at random within the final host. However, it is not the case at the population level since mating is restricted to worms from the same dog host. This conclusion is clear from individual inbreeding coefficient estimates with averages of 0.07 and 0.126 , which straddles the $F_{\mathrm{SC}}$ estimate of 0.100. The life cycle and multimodal nature of individual inbreeding values (Fig. 3) 
suggest a mixture of in- and outbreeding. Hence, heterozygosity at microsatellite loci reflects inbreeding history (Greeff et al., 2009). This level of inbreeding means that if a recessive resistant allele arises, it can be homozygous even when rare and can increase due to selection (Wright, 1921; Criscione et al., 2010; Beesley et al., 2017).

Similar to some internal parasites (Criscione et al. 2007; Steinauer, 2009), S. lupi shows no indication of a preference for, or an aversion to inbreeding. While this observation is not surprising for parasites that are restricted to find mating opportunities within a host, it is certainly not universal (Beltran et al., 2008; Beesley et al., 2017). As is expected for internal parasites (Steinauer, 2009), S. lupi did not suffer from inbreeding depression.

\section{Conclusion}

Our study has shown that selection can favour recessive resistance alleles, and that resistance alleles can spread effectively over short and long ranges.

\section{Acknowledgments}

We thank all the veterinarians and parasitologists involved in sample collection for this study - specifically, Prof Dawie Kok of ClinVet International Research Organization for the worm samples from the Grahamstown area and Dr Rick Last for the samples collected from the

Durban area. We thank Armanda Bastos for her comments, Patrick Meirmans, Jinlang Wang and two anonymous reviewers for their advice. We thank the Animal and Zoonotic Diseases Institutional Research Theme at the University of Pretoria for financial support. This work is based on the research supported in part by a number of grants from the National Research Foundation of South Africa (UID: 78566 (NRF RISP grant for the ABI3500) and grant number 
80678 to PdW and 77256 to JMG). The Grant holders acknowledge that opinions, findings and conclusions or recommendations expressed in any publication generated by the NRF supported research are that of the authors, and that the NRF accepts no liability whatsoever in this regard

\section{Supplementary material}

Supplementary data S1: Excel file of data.

Supplementary text: The use and meaning of $F$-statistics

\section{Data accessibility}

All genotyped microsatellite data is available in the supplementary material

\section{References}

Al-Sabi, M.N.S., Hansen, M.S., Chriél M., Holm, E., Larsen, G., 2014. Genetically distinct isolates of Spirocerca sp. from a naturally infected red fox (Vulpes vulpes) from Denmark. Vet. Parasitol. 205, 389-396.

Aroch, I., Rojas, A., Slon, P., Lavy, E., Segev, G., Baneth, G., 2015. Serological cross-reactivity of three commercial in-house immunoassays for detection of Dirofilaria immitis antigens with Spirocerca lupi in dogs with benign esophageal spirocercosis. Vet. Parasitol. 211, 303-305.

Bailey, W.S., 1972. Spirocerca lupi: a continuing inquiry. J. Parasitol. 58, 3-22. 
Beesley, N.J., Williams, D.J.L., Paterson, S., Hodgkinson, J., 2017. Fasciola hepatica demonstrates high levels of genetic diversity, a lack of population structure and high gene flow: possible implications for drug resistance. Int. J. Parasitol. 47, 11-20.

Belkhir, K., Borsa, P., Chikhi, L., Raufaste, N., Bonhomme, F., 1996-2004. GENETIX 4.05, logiciel sous WindowsTM pour la génétique des populations. Laboratoire Génome, Populations, Interactions, CNRS UMR 5000, Université de Montpellier II, Montpellier.

Beltran, S., Cézilly, F., Boissier, J. 2008. Genetic Dissimilarity between Mates, but Not Male Heterozygosity, Influences Divorce in Schistosomes. PLoS ONE 3, e3328.

Crawford, N.G., 2010. SMOGD: software for the measurement of genetic diversity. Mol. Ecol. Res. 10, 556-557.

Criscione, C.D., Poulin, R. and Blouin, M.S., 2005. Molecular ecology of parasites: elucidating ecological and microevolutionary processes. Mol. Ecol. 14, 2247-2257.

Criscione, C.D., Anderson, J.D., Raby, K., Sudimack, D., Subedi, J., Rai, D.R., Upadhayay, R.P., Jha, B., Williams-Blangero, S., Anderson, T.J.C., 2007. Microsatellite markers for the human nematode parasite Ascaris lumbricoides: development and assessment of utility. J. Parasitol. 93, 704-708.

Criscione, C.D., Anderson, J.D., Sudimack, D., Subedi, J., Upadhayay, R.P., Jha, B., Williams, K.D., Williams-Blangero, S., Anderson, T.J.C., 2010. Landscape genetics reveals focal transmission of a human macroparasite. PLoS Negl. Trop. Dis. 4, e665.

Criscione, C.D., Blouin, M.S., 2006. Minimal selfing, few clones, and no among-host genetic structure in a hermaphroditic parasite with asexual larval propagation. Evolution 60, 553-562. 
de Waal, P.J., Gous, A., Clift, S.J., Greeff, J.M., 2012. High within-host genetic variation of the nematode Spirocerca lupi in a high-density urban dog population. Vet. Parasitol. 187, 259-266.

Du Toit, C.A., Scholtz, C.H., Hyman, W.B., 2008. Prevalence of the dog nematode Spirocerca lupi in populations of its intermediate dung beetle host in the Tshwane (Pretoria) Metropole, South Africa. Onderstepoort J. Vet. 75, 315-321.

Earl, D.A., von Holdt, B.M., 2012. STRUCTURE HARVESTER: a website and program for visualizing STRUCTURE output and implementing the Evanno method, Conserv. Genet. Resour. 4, 359-361.

Ebbs, E.T., Loker, E.S., Davis, N.E., Flores, V., Veleizan, A., Brant, S.V., 2016. Schistosomes with wings: how host phylogeny and ecology shape the global distribution of Trichobilharzia quequedulae (Schistosomatidae). I. J. Parasitol. 46, 669-677.

Evanno, G., Regnaut, S., Goudet, J., 2005. Detecting the number of clusters of individuals using the software STRUCTURE: a simulation study. Mol. Ecol. 14, 2611-2620.

Excoffier, L., Lischer, H.E., 2010. Arlequin suite ver 3.5: a new series of programs to perform population genetics analyses under Linux and Windows. Mol. Ecol. Res. 10, 564-567.

Fitzsimmons, W.M., 1960. Observations on the incidence, pathology and aetiology of Spirocerca lupi infestation in Nyasaland. Br. Vet. J. 116, 272-274.

Greeff, J.M., Jansen van Vuuren, G.J., Kryger, P., Moore, J.C., 2009. Outbreeding and possibly inbreeding depression in a pollinating fig wasp with a mixed mating system. Heredity 102, 349-356. 
Giannelli, A., Baldassarre, V., Ramos, R.A., Lia, R.P., Furlanello, T., Trotta, M., Dantas-Torres, F., Baneth, G., Otranto, D., 2014. Spirocerca lupi infection in a dog from southern Italy: an "old fashioned” disease? Para. Res. 113, 2391-2394.

Goudet, J., 1995. FSTAT (version 1.2): a computer program to calculate $F$-statistics. J. Hered. $86,485-486$.

Greyling, L.M., Grobler, P.J., van der Bank, H.F., Kotze, A., 2004. Genetic characterization of a domestic dog Canis familiaris breed endemic to South African rural areas. Acta Theriol. 49, 369-382.

Hedrick, P.W., 2000. Genetics of populations $2^{\text {nd }}$ ed. Jones and Bartlett Publishers, Sudbury. Hubisz, M.J.,Falush, D., Stephens, M., Pritchard, J., 2009. Inferring weak population structure with the assistance of sample group information. Mol. Ecol. Res. 9, 1322-1332.

Johnson, P.C.D., Webster, L.M.I., Adam, A., Buckland, R., Dawson, D.A., Keller, L.F., 2006. Abundant variation in microsatellites of the parasitic nematode Trichostrongylus tenius and linkage to tandem repeat. Mol. Biochem. Parasitol. 148, 210-218.

Kok, D.J., Schenker, R., Archer, N.J., Horak, I.G., Swart, P., 2011. The efficacy of milbemycin oxime against pre-adult Spirocerca lupi in experimentally infected dogs. Vet. Parasitol. 177, 111-118.

Margolis, L., Esch, G.W., Holmes, J.C., Kuris, A.M., Schad, G.A., 1982. The use of ecological terms in parasitology (report of an ad hoc committee of the American Society of Parasitologists). J. Parasitol. 68, 131-133.

Mazaki-Tovi, M., Baneth, G., Aroch, I., Harrus, S., Kass, P.H., Ben Ari, T., Zur, G., Aizenberg, I., Bark, H., Lavy, E., 2002. Canine spirocercosis: clinical, diagnostic, pathologic and epidemiologic characteristics. Vet. Parasitol. 107, 235-250. 
Meirmans, P.G., 2006. Using the AMOVA framework to estimate a standardized genetic differentiation measure. Evolution 60, 2399-2402.

Meirmans, P.G., Hedrick, P.W. 2011. Assessing population structure: $F_{\text {ST }}$ and related measures. Molec. Ecol. Res. 11, 5-18.

Nadler, S.A., 1995. Microevolution and the genetic structure of parasite populations. J. Parasitology. 81, 395-405.

Oryan, A., Sdajjadi, S.M., Mehrabani, D., Kargar, M., 2008. Spirocercosis and its complications in stray dogs in Shiraz, southern Iran. Veterinarni Medicina. 53,617-624.

Pamilo, P. Crozier, R.H., 1982. Measuring genetic relatedness in natural populations: methodology. Theor. Popul. Biol. 21, 171-193.

Paterson, S., Fischer, M.C., Viney, M.E., 2000. Inferring infection processes of a parasitic nematode using population genetics. Parasitology120, 185-194.

Pritchard, J.K., Stephens, M., Donnelly, P., 2000. Inference of population structure using multilocus genotype data. Genetics $155,945-959$.

Prugnolle, F., de Meeûs, T., Durand, P., Sire, C., Théron, A., 2002. Sex-specific genetic structure in Schistosoma mansoni: evolutionary and epidemiological implications. Molec. Ecol. $11,1231-1238$.

Prugnolle, F., Roze, D., Théron, A.,de Meeûs, T., 2005a. F-statistics under alternation of sexual and asexual reproduction: a model and data from schistosomes (platyhelminth parasites). Molec. Ecol. 14, 1355-1365.

Prugnolle, F., Liu, H. de Meeûs, T., Balloux, F., 2005b. Population genetics of complex lifecycle parasites: an illustration with trematodes. Int. J. Parasitol. 35, 255-263. 
R Core Team, 2016. R: A language and environment for statistical computing. $R$ Foundation for Statistical Computing, Vienna, Austria. URL https://www.R-project.org/.

Reid, K., Mitha, J.R., Greeff, J.M., de Waal, P.J., 2015. Molecular genomics resource for the parasitic nematode Spirocerca lupi: Identification of 149 microsatellite loci using FIASCO and next generation sequencing. Mol. Biochem. Parasitol. 203, 1-4.

Soulsby, E.J.L., 1982. Helminths, arthropods and protozoa of domesticated animals, $7^{\text {th }}$ ed. Baillière Tindall, London.

Steinauer, M.L., 2009. The sex lives of parasites: Investigating the mating system and mechanisms of sexual selection of the human pathogen Schistosoma mansoni. I. J. Parasitol. 39, 1157-1163.

Steinauer, M.L., Blouin, M.S., Criscione, C.D. 2010. Applying evolutionary genetics to schistosome epidemiology. Inf. Genet. Evol. 10, 433-443.

Théron, A., Sire, C., A. Rognon, A., Prugnolle, F., P. Durand, P., 2004. Molecular ecology of Schistosoma mansoni transmission inferred from the genetic composition of larval and adult infrapopulations within intermediate and definitive hosts. 129, 571-585.

van der Merwe, L.L., Kirberger, R.M., Clift, S., Williams, M., Keller, N., Naidoo, V., 2008. Spirocerca lupi infection in the dog: a review. Vet. J. 176, 294-309.

Wang, J., 2011. COANCESTRY: a program for simulating, estimating and analysing relatedness and inbreeding coefficients. Mol. Ecol. Res. 11, 141-145.

Wang, J., 2015. Does $G_{\text {ST }}$ underestimate genetic differentiation from marker data? Molec. Ecol. $24,3546-3558$.

Weir, B.S., Cockerham, C.C., 1984. Estimating $F$-statistics for the analysis of population structure. Evolution 38, 1358-1370. 
Whitlock, M.C., McCauley, D.E., 1999. Indirect measures of gene flow and migration: $F_{\mathrm{ST}} \neq$ $1 /(4 N m+1)$. Heredity $82,117-125$.

Wright, I., Stafford, K., Coles, G., 2016. The prevalence of intestinal nematodes in cats and dogs from Lancashire, north-west England. J. Small Anim. Pract. 57, 393-395.

Wright, S., 1921. Systems of mating. Genetics 6, 111-178.

Wright, S., 1931. Evolution in Mendelian populations. Genetics 16, 97-159. 